\title{
Philosophiques
}

\section{Sous la direction de Lizette Jalbert et Lucille Beaudry, Les métamorphoses de la pensée libérale. Sur le néo-libéralisme actuel, Québec, Presses de l’Université du Québec, 1987, 237 p.}

\section{Jacques G. Ruelland}

Volume 17, numéro 1, printemps 1990

URI : https://id.erudit.org/iderudit/027115ar

DOI : https://doi.org/10.7202/027115ar

Aller au sommaire du numéro

Éditeur(s)

Société de philosophie du Québec

ISSN

0316-2923 (imprimé)

1492-1391 (numérique)

Découvrir la revue

Citer ce compte rendu

Ruelland, J. G. (1990). Compte rendu de [Sous la direction de Lizette Jalbert et Lucille Beaudry, Les métamorphoses de la pensée libérale. Sur le néo-libéralisme actuel, Québec, Presses de l'Université du Québec, 1987, 237 p.] Philosophiques, 17(1), 162-163. https://doi.org/10.7202/027115ar d'utilisation que vous pouvez consulter en ligne. 
Sous la direction de LIZETTE JALBERT et LUCILLE BEAUDRY, Les métamorphoses de la pensée libérale. Sur le néo-libéralisme actuel, Québec, Presses de l'Université du Québec, 1987, 237 p.

$$
\text { par Jacques G. Ruelland }
$$

Cet ouvrage composé de neuf textes est le fruit de la collaboration de douze auteurs. Une seule question unifie tous les points de vue qui y sont exprimés : quelle est la nature du libéralisme actuel?

On peut soutenir que le cours du $\mathrm{XX}^{\mathrm{e}}$ siècle a été coupé en deux par la II $^{e}$ Guerre mondiale. Depuis 1945, les États occidentaux se sont employés, de plus en plus, à pallier à l'inégalité des conditions d'existence des citoyens. Le climat de désenchantement des années soixante-dix les a forcés à repenser leur mission providentielle, et à inventer de nouveaux moyens de relancer le capitalisme : cette recherche d'un nécessaire ajustement est le néo-libéralisme. Quelle est sa portée politique? En quoi est-il si nouveau? Son succès ne masque-t-il pas une confusion générale sur l'orientation et le sens actuels de la politique? Voilà les problèmes précis que ce livre souligne, et vers lesquels il tente de lancer quelques pistes de réponses.

La pensée néo-libérale est réfractaire à tout changement qui n"incluerait pas l'idée de conservation, et n'affiche dès lors aucune représentation de l'avenir. L'effondrement de l'hégémonie keynésienne, la disqualification du marxisme et le marasme de la gauche sont autant d'étapes qui justifient peutêtre le retour de l'économisme, où l'instance économique domine le politique. Mais ce renouveau, parce qu'il s'allie au conservatisme, révèle en fair que le néo-libéralisme actuel n'est qu'une des nombreuses métamorphoses de la 
pensée libérale du XIX ${ }^{e}$ s., dont la signification a varié considérablement à travers les âges. Le conservateur est préoccupé avant tout par la protection et la défense de l'ordre social contre toute ingérence de l'État dans les affaires sociales; il veut effacer les conquêtes de la social-démocratie. C'est ainsi que France Giroux et Maurice Lagueux, qui sont au nombre des auteurs de ce livre, trouvent le néo-libéralisme passéiste; par contre, la position inverse est soutenue par Dorval Brunelle, pour qui il est erroné de croire qu'un économiste comme Hayeck préconise le libéralisme classique.

Tour à tour sont examinés les phénomènes suivants : la signification et la portée politique du néo-libéralisme (Lucille Beaudry et Lizette Jalbert), la soumission de l'État aux lois du marché (François Houle), l'État de droit (Dorval Brunelle), la nouvelle droite américaine (Harold Chorney, Marguerite Mendell et Philip Hansen), la théorie néo-classique américaine (Paul-Marcel Roy), les néo-Autrichiens et les néo-classiques (Jacques Peltier), la gauche (Maurice Lagueux), la gouvernabilité de l'État-providence (Richard Groulx) et les racines historiques du néo-libéralisme qui en font en fait un rétrolibéralisme (France Giroux). Ainsi mis à nu, examiné sous toutes ses facettes, le néo-libéralisme révèle alors une chose surprenante : selon la conception néo-libérale de l'ordre, la solution à la crise actuelle de l'économie consiste uniquement à réitérer le bien-fondé des lois antérieures de fonctionnement, et cette conception conservatrice étouffe la spontanéité immanente à l'évolution sociale.

Le néo-libéralisme s'accommode parfois fort bien d'une démocratie politique, mais ne tolère pas la démocratie économique. Dans le climat économique et culturel surmené des pays occidentaux d'aujourd' hui, comment ne pas voir dans la pensée néo-libérale le ferment d'un éclatement social ? Lizette Jalbert et Lucille Beaudry décèlent là l'affirmation d'une tendance à l'autoritarisme ; par contre, France Giroux estime que le nouvel ordre social en est exempt, car le projet néo-libéral préconise que l'ère de l'autonomie (et d'une certaine autogestion liée à l'espace social libertaire) se substitue à celle de l'hétéronomie. Mais, conclut ce livre, les assises de la révolution libéraleconservatrice de la société occidentale pourraient bien être plus fragiles qu'il n'y paraît. C'est en tout cas ce que tente de démontrer cet essai, qui soulève de nombreuses questions et suscite des débats très intéressants et très actuels. $\grave{A}$ la façon d'un révélateur photographique, il permet de discerner les images latentes que masque mal la vogue actuelle du libéralisme, les faiblesses d'une pensée vieillie en mal de métamorphose et de renouveau réel.

Département de pbilosophie

Collège Edouard-Montpetit 